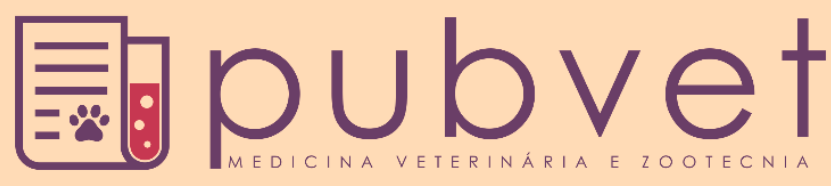

https://doi.org/10.31533/pubvet.v14n6a586.1-10

\title{
Tumor venéreo transmissível na córnea de um cão: relato de caso
}

\author{
Vagner José Teixeira de Souza $^{1^{*} \bullet}$, Maria Cecilia de Lima Rorig ${ }^{2} \bullet$, Lucas Matheus \\ Possamai $^{1 \oplus}$, Caio Henrique Ferreira ${ }^{1}$ \\ ${ }^{I}$ Discente do curso de Medicina Veterinária da Pontifícia Universidade Católica do Paraná. Toledo - PR Brasil. \\ ${ }^{2}$ Médico(a) veterinário(a) docente do curso de Medicina Veterinária da Pontifícia Universidade Católica do Paraná. Toledo - PR Brasil. \\ *Autor para correspondência, E-mail: vagner.teixeira2021@outlook.com.
}

Resumo. O tumor venéreo transmissível (TVT) consiste em uma neoplasia de células redondas com grande potencial de difusão entre cães, independente do sexo, adultos e sexualmente ativos. Na grande maioria dos casos, o local de desenvolvimento do tumor é a genitália externa de cães, mas pode vir a acometer outros locais do corpo do animal por meio de metástases ou implantação por contato. A neoplasia não possui predisposição racial apesar de cães SRD serem os mais comumente acometidos. O objetivo foi relatar o atendimento de um cão macho, adulto, com diagnóstico de tumor venéreo transmissível em córnea de olho esquerdo. O animal chegou à Clínica Veterinária da PUCPR apresentando uma neoformação de consistência firme e aspecto rosado com presença de tecido de granulação recobrindo toda a superfície ocular esquerda e com implantação em córnea. $\mathrm{O}$ diagnóstico se deu por meio da citologia por imprint em lâmina corada em panótico rápido e submetido à microscopia que revelou a presença de células tumorais redondas com citoplasma escasso e núcleo grande e arredondado com presença de figuras mitóticas ao fundo da lâmina. O paciente foi submetido à quimioterapia por meio do Sulfato de Vincristina associado à Ivermectina $1 \%$ como agente potencializador do efeito antineoplásico da Vincristina e fármaco imunoestimulante, em um total de seis sessões, atingindo-se remissão total da neoplasia e recuperação da visão do olho afetado. Este trabalho demonstra a importância do diagnóstico, a terapêutica empregada e os resultados obtidos por meio da terapia antineoplásica.

Palavras chave: cão, olho, terapia antineoplásica, tumor venéreo transmissível

\section{Transmissible venereal tumor in the cornea of a dog: case report}

Abstract. The transmissible venereal tumor (TVT) consists of a round cell neoplasm with great potential for diffusion among dogs, regardless of sex, adults and sexually active. In most cases, the tumor develope itself on the external side of the genitalia of dogs, but it can affect other parts of the body of animals through metastasis or implantation by contact. The neoplasm has no racial predisposition despite the fact that SRD dogs are the most commonly affected. The objective was to describe the care of an adult male dog diagnosed with a transmissible venereal tumor in the cornea of the left eye. The animal arrived at the Veterinary Clinic of PUCPR presenting a new formation of firm consistency and pink appearance, with the presence of granulation tissue, covering the entire left ocular surface and implanted in the region. The diagnosis was made by means of cytology to print in color in the fast panotic and submitted to microscopy that revealed the presence of round tumor cells with scarce cytoplasm and a large rounded nucleus with the presence of mitotics figures at the bottom of the substance. The patient was submitted to chemotherapy by means of Vincristine Sulfate associated with Ivermectin $1 \%$ as a potentiating agent of Vincristine antineoplastic effect and immunostimulating drug, in a total of six sessions, 
achieving total remission of neoplasia and full recovery of the vision of the affected eye. This work demonstrates the importance of diagnosis, the therapy used and the results obtained through antineoplastic therapy.

Keywords: dog, eye, antineoplastic therapy, transmissible venereal tumor

\section{Tumor venéreo transmisible en la córnea de un perro: reporte de caso}

Resumen. El tumor venéreo transmisible (TVT) consiste en una neoplasia de células redondas con gran potencial de difusión entre perros, independientemente de su sexo, adultos y sexualmente activos. En la mayoría de los casos, el sitio de desarrollo tumoral es un genital externo de los perros, pero puede afectar a otras partes del cuerpo de los animales a través de metástasis o implantación por contacto. La neoplasia no tiene predisposición racial a pesar de que los perros criollos son los más afectados. El objetivo fue informar el cuidado de un perro macho adulto diagnosticado con un tumor venéreo transmisible en la córnea del ojo izquierdo. El animal llegó a la Clínica Veterinaria de PUCPR presentando una neoformación de consistencia firme y apariencia rosada, con presencia de tejido de granulación, cubriendo toda la superficie ocular izquierda e implantada en la región corneal. El diagnóstico se realizó mediante citología imprint en lámina de coloración rápida y sometida a microscopía que reveló la presencia de células tumorales redondas con escaso citoplasma y un núcleo grande y redondeado con la presencia de figuras mitológicas en el fondo de la lámina. El paciente fue sometido a quimioterapia mediante sulfato de vincristina asociado con ivermectina al $1 \%$ como agente potenciador del efecto antineoplásico de vincristina y fármaco inmunoestimulador, en un total de seis sesiones, logrando la remisión total de la neoplasia y la revisión de la visión del ojo afectado. Este trabajo demuestra la importancia del diagnóstico, la terapia utilizada y los resultados obtenidos a través de la terapia antineoplásica.

Palabras clave: perro, ojo, terapia antineoplásica, tumor venéreo transmisible

\section{Introdução}

De acordo com Daleck et al. (2016), o tumor venéreo transmissível (TVT) caracteriza-se por uma neoplasia de células redondas altamente contagiosa, afetando principalmente órgãos genitais externos de cães. Possui uma agressividade questionável e raramente culmina com a morte do animal (Siddle \& Kaufman, 2013). A transmissão ocorre por via sexual, podendo ser disseminado mecanicamente por intermédio de interações entre animais saudáveis e doentes como lambeduras, mordeduras ou arranhões (Filgueira, 2010) e até mesmo por transplantes experimentais (F. G. A. Santos et al., 2001).

A ocorrência de metástases é relatada em menos de $5 \%$ dos casos, podendo esta ocorrer por via hematógena ou linfática (Nielsen \& Kennedy, 1990). A neoplasia pode acometer pele, cavidade nasal e olhos (Huppes et al., 2014; Santos et al., 2008) e de forma esporádica o sistema nervoso central. Amaral et al. (2004) denotaram que a localização mais corriqueira do TVT é a genital, seguida pela forma cutânea, cavidade nasal e linfonodos superficiais. A presença do tumor envolvendo a área ocular é menos comum, sendo apontadas como causas desta localização ectópica as metástases ou implantação por contato (Ginel et al., 1995).

O diagnóstico baseia-se em histórico, exame clínico e exames complementares, sendo a citologia por imprint em lâmina ou aspirativa por agulha fina as mais empregadas, consistindo em um exame de fácil execução e baixo custo (Filgueira, 2010; Santos et al., 2008; Santos et al., 2001; Santos \& Shimizu, 2010).

$\mathrm{Na}$ terapêutica, utiliza-se o Sulfato de Vincristina como agente quimioterápico único em administrações semanais por via endovenosa, protocolo esse o mais eficaz, atingindo cerca de $90 \%$ de efetividade (Drumond et al., 2013; Eze et al., 2014).

Este relato tem por objetivo apresentar a ocorrência do tumor venéreo transmissível na córnea de um cão, bem como a terapia instituída e os resultados obtidos, dada a importância da neoplasia na espécie canina e a baixa ocorrência do tumor na forma ocular. 


\section{Relato de caso clínico}

Foi atendido na Clínica Veterinária Universitária (Clivet) da Pontifícia Universidade Católica do Paraná, campus Toledo, um cão macho, adulto, não castrado, sem raça definida, pesando $9,7 \mathrm{~kg}$. A queixa principal por parte da tutora era a presença de uma massa no olho esquerdo. Esta relatou ainda que o animal possuía acesso à rua e, por conseguinte, contactantes. Quando questionada a respeito da alimentação, disse que o cão apresentava normorexia e normodipsia.

Mediante exame físico, constatou-se escore de condição corporal 2, mucosas normocoradas, sem a presença de desidratação, frequência cardíaca de 132 batimentos por minuto (bpm), tempo de preenchimento capilar de 2 segundos (TPC), pulso forte e temperatura retal de $38,6^{\circ} \mathrm{C}$. Não foram denotadas alterações mediante palpação dos gânglios linfáticos e o animal não demonstrou dor durante a palpação abdominal.

No exame oftálmico do olho esquerdo percebeu-se a presença de uma neoformação de consistência firme e aspecto rosado com presença de tecido de granulação recobrindo toda a superfície ocular e implantado sobre a camada córnea. $\mathrm{O}$ animal apresentava blefaroespasmo e não conseguia realizar a oclusão palpebral por ocasião da presença da massa. Para facilitar o exame clínico do olho, administrouse o colírio anestésico à base de Proximetacaína $\left(\right.$ Anestalcon $\left.^{\circledR}\right) 2$ gotas.

Devido à presença da massa, havia o comprometimento total da visão do olho esquerdo do animal. O diagnóstico presuntivo foi de tumor venéreo transmissível (TVT), realizando-se então uma citologia por imprint em lâmina para diagnóstico definitivo, processo o qual foi facilitado pela administração do colírio anestésico acima mencionado. A inspeção da mucosa peniana não evidenciou a presença de massas tumorais. Por meio análise citológica, denotou-se a presença de células redondas, com citoplasma escasso a moderado, por vezes apresentando pequenos vacúolos, e núcleo único, paracentral, grande e arredondado e nucléolos pouco evidentes. O resultado da citologia foi compatível com Tumor Venéreo Transmissível (TVT) (Figuras 1 A e B).

Diante do resultado do laudo citológico, instituiu-se terapia antineoplásica à base de Sulfato de Vincristina por via endovenosa na dose de $0,5 \mathrm{mg} / \mathrm{m}^{2}$ associada à Ivermectina $1 \%$ (Ivomec ${ }^{\circledR} 1 \%$ injetável) por via subcutânea na dose de $0,4 \mathrm{mg} / \mathrm{kg}$ como terapia potencializadora do efeito do antineoplásico e imunoestimulante, caracterizando a primeira aplicação como $\mathrm{D}=0$. A tutora relatou nesta ocasião que o cão já havia sido submetido à terapia antineoplásica por meio do Sulfato de Vincristina para o tratamento de TVT em cavidade nasal há aproximadamente quatro meses.

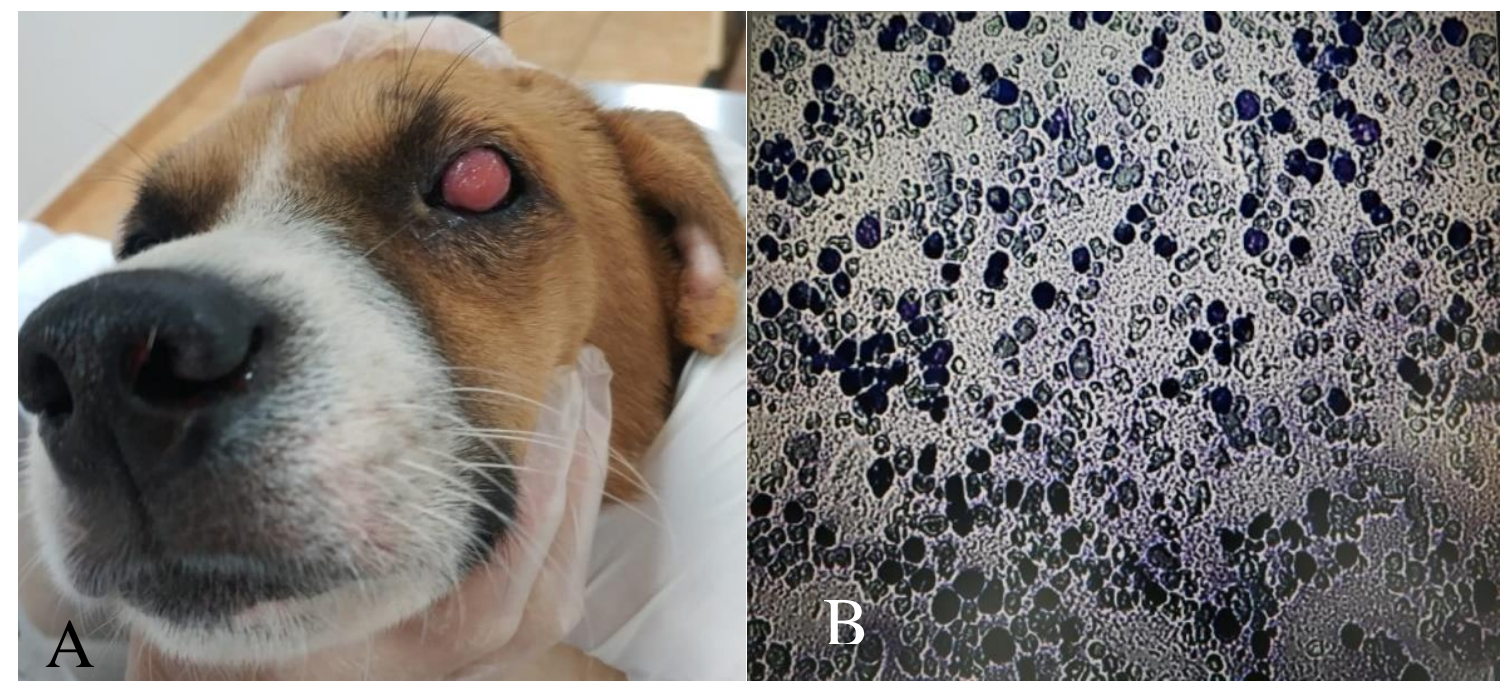

Figura 1. Fotografia evidenciando a presença de uma neoformação rósea e de consistência friável recobrindo todo o olho esquerdo do animal compatível com tumor venéreo transmissível (TVT) $\mathrm{D}=0$ do início do tratamento com Sulfato de Vincristina (A). Fotografia de lâmina obtida por imprint da massa ocular submetida à coloração de panótico evidenciando a presença de células de TVT, aumento de 400x (B).

Decorridos sete dias da administração do antineoplásico, o cão retornou à Clínica Veterinária universitária para avaliação da regressão tumoral e nova submissão à terapia. Solicitou-se hemograma 
para realizar acompanhamento dos parâmetros hematológicos do animal, sendo que não foi evidenciada nenhuma alteração digna de nota. Observou-se discreta regressão da neoformação (Figuras 2 A e B), entretanto, a remissão foi abaixo do esperado e, além disso, o animal apresentava epistaxe levando a crer que o tumor em cavidade nasal não havia involuído totalmente. A presença de massas tumorais não foi evidenciada na inspeção da cavidade nasal, não obstante, a possibilidade de o tumor estar localizado em planos mais profundos das vias respiratórias não foi descartada. Por conta de tais fatores, a dose do Sulfato de Vincristina foi alterada para $0,7 \mathrm{mg} / \mathrm{m}^{2}$. A Ivermectina manteve-se na mesma dosagem $(0,4 \mathrm{mg} / \mathrm{kg})$. Novo retorno foi instituído para sete dias após a segunda administração do quimioterápico.

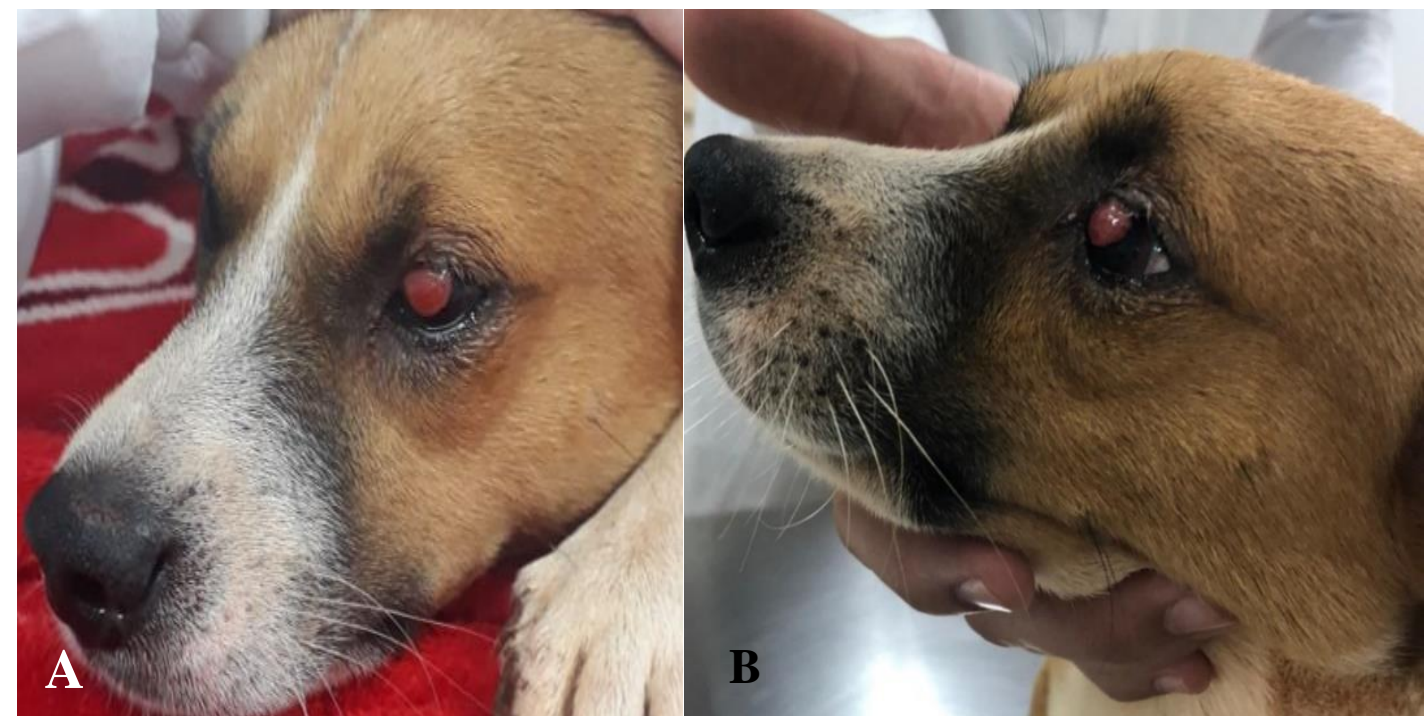

Figura 2. (A) e (B). D=7 após início da terapia antineoplásica com Sulfato de Vincristina evidenciando discreta redução da massa tumoral.

No $\mathrm{D}=14$ após início da terapia, observou-se uma resposta satisfatória ao tratamento haja vista a redução mais claramente notável do tumor (Figura 3). Nenhum evento anormal foi relatado pela tutora e não foi observado qualquer efeito colateral da terapia. Um hemograma foi realizado para se obter o perfil hematológico do animal em decorrência da quimioterapia, sendo que alterações não foram evidenciadas. Assim, tendo em vista a ausência de alterações nos parâmetros hematológicos, a mesma dosagem do Sulfato de Vincristina foi mantida, bem como da Ivermectina.

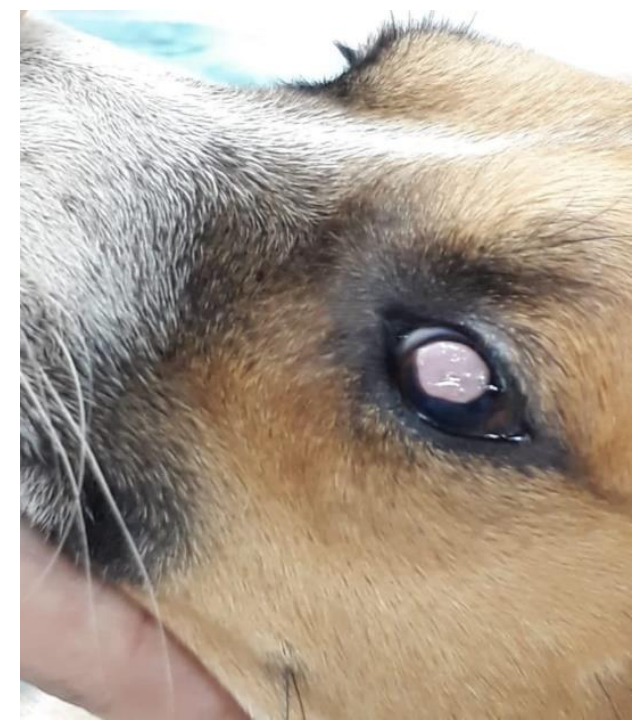

Figura 3. $D=14$ após início da terapia com Sulfato de Vincristina evidenciando uma involução mais perceptível da massa tumoral.

Novo retorno ocorreu no $\mathrm{D}=21$ ao início do tratamento. A massa tumoral apresentava-se ainda mais reduzida que na sessão anterior (Figuras 4 A e B). A tutora relatou que o animal se alimentava bem e 
não apresentava qualquer sintomatologia anormal. Como de praxe, solicitou-se um hemograma, o qual detectou um decréscimo dos leucócitos para o seu valor mínimo (6000 leucócitos/ $\mu$; valores de referência: 6000 a 17000 leucócitos/ $\mu 1$ ). Assim sendo, procedeu-se a mais uma aplicação do Sulfato de Vincristina na dose de $0,7 \mathrm{mg} / \mathrm{m}^{2} \mathrm{e}$, tendo em vista a diminuição das células de defesa circulantes possivelmente por efeito do antineoplásico, a dose da Ivermectina foi aumentada para $0,6 \mathrm{mg} / \mathrm{kg}$ administrada via subcutânea. A tutora foi orientada a um novo retorno 7 dias após.

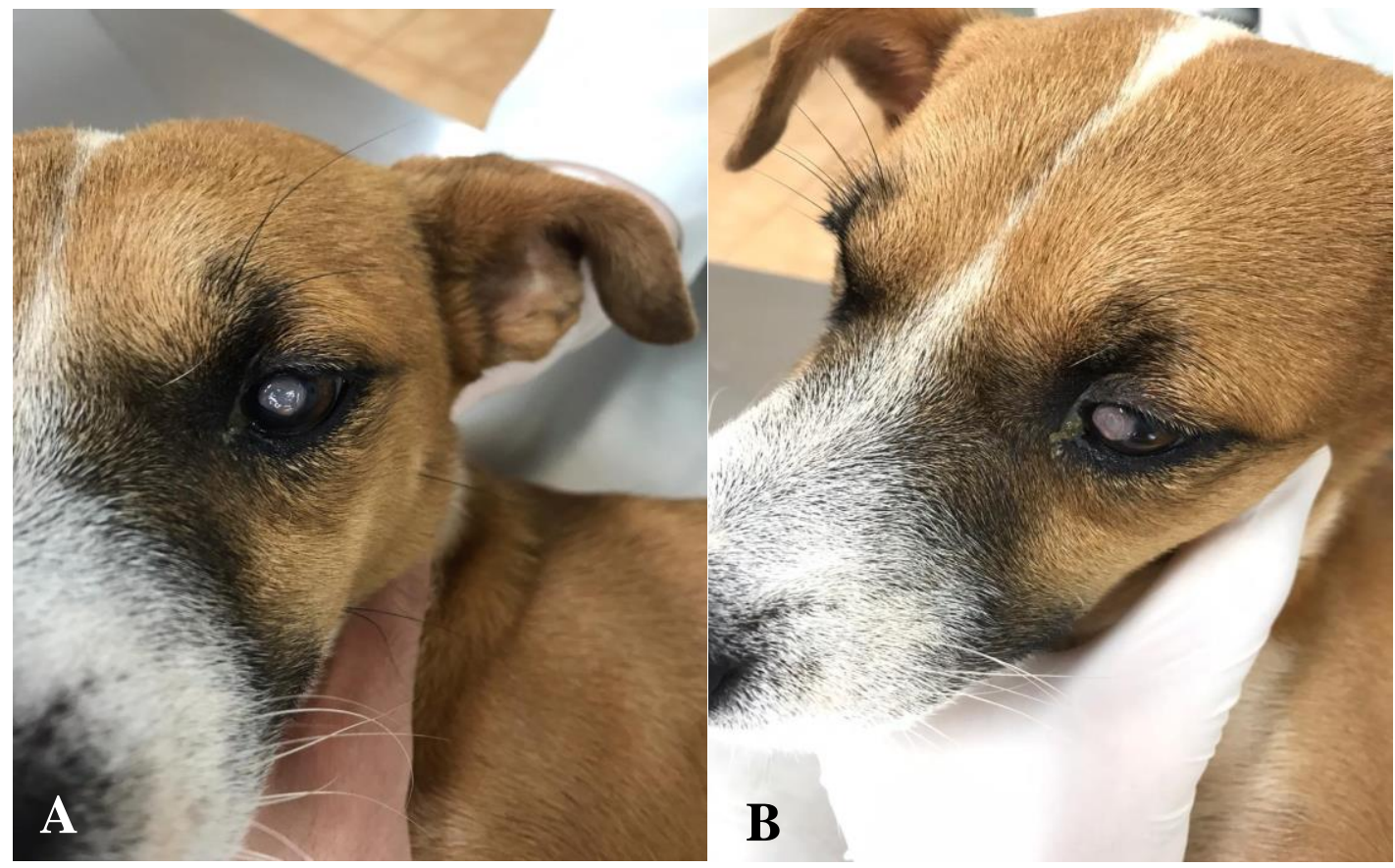

Figura 4. D=21 após início do tratamento em que é perceptível uma involução significativa do TVT em córnea de olho esquerdo vista frontal (A) e lateral (B).

No $\mathrm{D}=28$ observou-se uma remissão quase que total da neoplasia (figura 5). O animal apresentavase saudável e sem nenhum efeito colateral decorrente da terapia com Sulfato de Vincristina. Por meio do exame oftálmico do olho esquerdo foi possível constatar a presença de reflexo de resposta à ameaça e de reflexo pupilar, constatando-se assim que o animal havia recuperado a visão do olho afetado. De acordo com o hemograma solicitado não foram detectadas alterações. Procedeu-se então à quinta administração do Sulfato de Vincristina e da Ivermectina na mesma dosagem da sessão anterior.

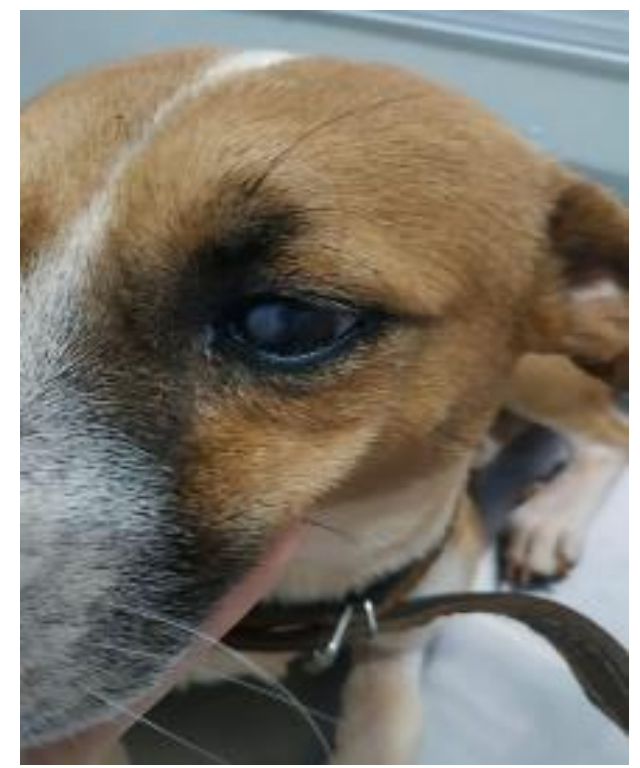

Figura 5. $\mathrm{D}=28$ após início do tratamento. Observa-se uma involução quase completa da massa tumoral e presença de uma leve opacidade no local da lesão. 
No $\mathrm{D}=35$ do início da terapia, realizou-se a última administração do antineoplásico. $\mathrm{O}$ animal apresentava-se aparentemente hígido e a tutora negou a ocorrência de qualquer evento anormal. $\mathrm{O}$ hemograma solicitado não evidenciou alterações dignas de nota. Assim, a dosagem do Sulfato de Vincristina e da Ivermectina permaneceram inalteradas. Por intermédio do exame oftálmico, observouse uma completa involução da massa tumoral, o que demonstrou a efetividade do tratamento com Sulfato de Vincristina (Figuras 6 A e B). O animal recuperou totalmente a visão do olho afetado, apresentando apenas uma pequena área de opacidade no local da lesão tumoral.

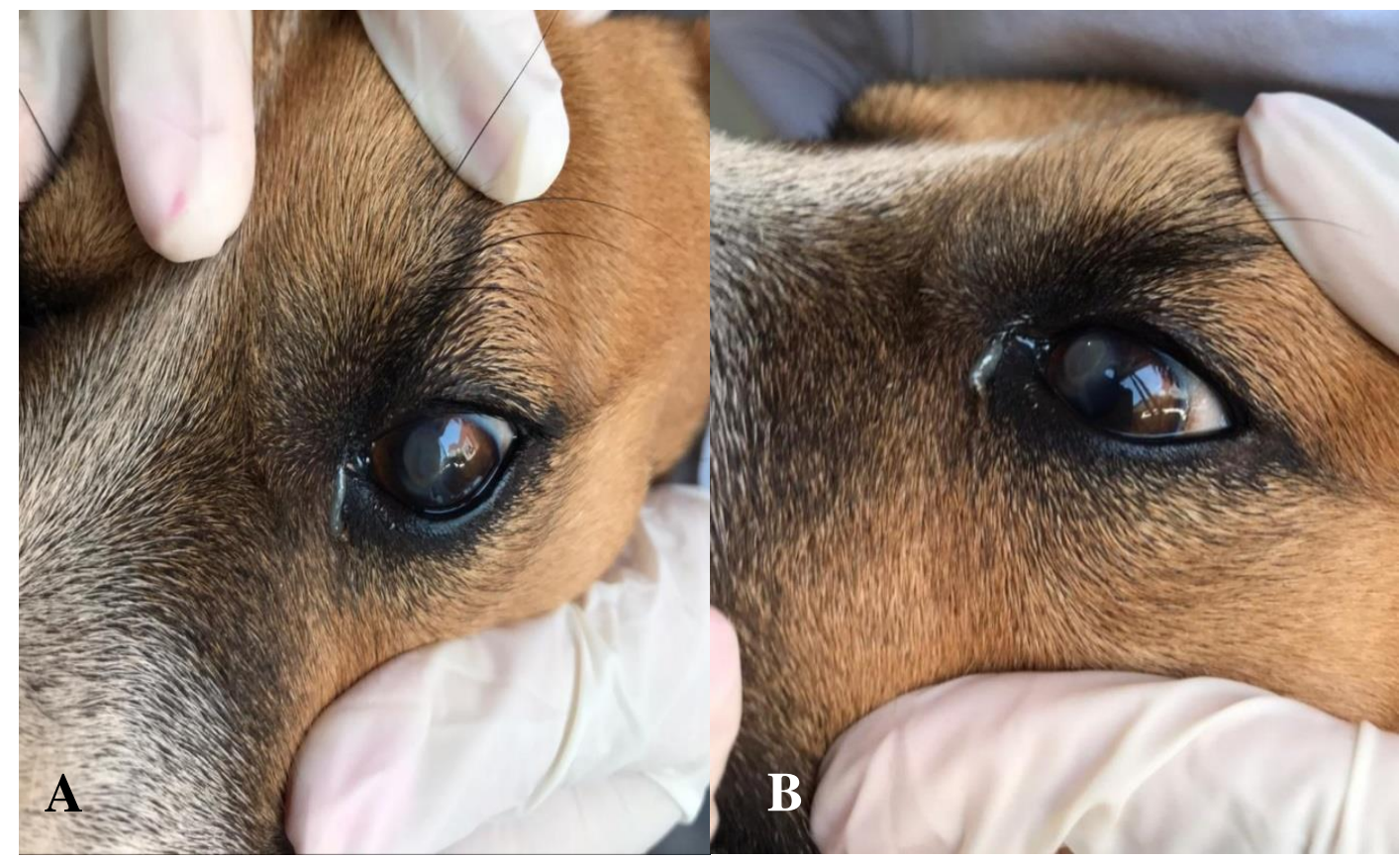

Figura 6. Evidenciação da completa remissão tumoral e visualização de uma pequena área de opacidade ocular no local da lesão vista frontal (A) e lateral (B).

\section{Discussão}

Amaral et al. (2012) caracterizaram o Tumor Venéreo Transmissível canino (TVT) como uma neoplasia maligna e contagiosa de ocorrência corriqueira entre cães. Historicamente, o primeiro relato de TVT na espécie canina foi descrito em 1820 por Huzard, não obstante, Sticker em 1904, foi quem o catalogou detalhadamente classificando-o como um linfossarcoma, sendo a neoplasia também designada por Linfossarcoma de Sticker (Santos et al., 2001).

Sua origem histológica não é totalmente esclarecida, conquanto, segundo Costa (2008), estudos histoquímicos convergiram a um tipo histiocítico de origem celular. De acordo com Mc Ewen Eg (2001), a localização mais corriqueira do TVT é a genitália externa e ainda pode ser encontrado extragenital de forma associada ou isolada, entretanto, é dito que a maioria das lesões extragenitais é decorrente de um foco inicial, ocorrendo, assim, de forma concomitante. Em casos em que neoplasia ocorre de forma a não envolver as genitálias, como é o caso deste relato, pode culminar em uma maior dificuldade ou retardo no diagnóstico e até mesmo a distinção do tumor venéreo transmissível de demais neoplasias de células redondas (Miller et al., 2013; Mozos et al., 1996).

Casos de TVT extragenitais em cães já foram relatados, porém, a maioria dos acontecimentos extragenitais decorrem de heteroimplantação ou autoimplantação, sendo a ocorrência de metástases via hematógena ou linfática, consideradas incomuns (Amaral et al., 2012; Rodrigues et al., 2001). Tendo em vista os autores supracitados, o caso deste relato pode ser considerado uma implantação por contato, uma vez que a localização anatômica do olho facilita a implantação das células tumorais mediante contato com outros animais afetados, haja vista que o animal tinha acesso à rua. Não obstante, a possibilidade de metástase tumoral, apesar de incomum, não pode ser descartada, pois apesar de não ser evidenciada a presença de massas tumorais em cavidade nasal, o animal apresentava o histórico de tratamento da neoplasia nessa região e apresentou epistaxe no $\mathrm{D}=7$ do início da terapia. 
Amaral et al. (2004) relataram a ocorrência do TVT na córnea de um cão, sendo que não foi possível definir com veemência a via de acesso exata (metástase ou implantação) das células neoplásicas ao globo ocular, como no caso deste relato. Entretanto, segundo os mesmos autores, nestes casos, a implantação é a via mais frequente, levando-se acreditar em sua ocorrência.

Pelo fato de o animal já ter sido submetido anteriormente à terapia antineoplásica por conta de um TVT em cavidade nasal, pode-se inferir também que, possivelmente tal terapia possa ter sido realizada por um período inadequado de tempo, tendo em vista que em casos de TVT em que o tratamento é realizado até completa involução tumoral, as recidivas são mínimas (Batista et al., 2007; Filgueira, 2010; Raposo, 2014; Santos et al., 2001) e que a resistência tumoral é uma hipótese a ser descartada, uma vez que o tumor respondeu satisfatoriamente ao Sulfato de Vincristina.

Brandão et al. (2002) denotaram a presença do tumor na região ocular de cães em apenas $2 \%$ dos casos estudados, precedida pela localização em genitálias, pele e cavidade oral. Para Daleck et al. (2008) apesar de não haver predisposição racial na incidência do TVT, estudos realizados no Brasil atestam cães sem raça definida (SRD) como os mais acometidos pela neoplasia, como é o caso do presente relato.

Dentre os métodos de diagnóstico, é dito que os métodos de citologia por imprint ou aspirativa por agulha fina (PAAF) são considerados de fácil execução e grande importância, uma vez que o aspecto celular do tumor possui uma natureza peculiar que na sua maioria é de fácil caracterização (Amaral et al., 2004), sendo o primeiro método descrito, utilizado no diagnóstico definitivo deste caso clinico.

Na microscopia, é possível visualizar células com núcleos centrais, grandes, com cromatina agregada e nucléolos excêntricos. O citoplasma escasso, granular e normalmente apresenta a presença de vacúolos (Amaral et al., 2012; Costa, 2008). A descrição é semelhante ao que foi evidenciado neste relato, com a presença de células com núcleo único, grande e arredondado e o citoplasma celular escasso e, por vezes apresentando pequenos vacúolos.

Em se tratando do perfil hematológico do animal mediante a terapia antineoplásica, é dito que o Sulfato de Vincristina administrado em doses semanais por um período de quatro semanas, pode culminar em redução da proliferação da linhagem eritróide, resultando em anemia hipoplásica. Ademais, o referido antineoplásico pode também promover uma supressão da atividade granulopoiética, culminando em uma redução significativa na contagem de leucócitos globais resultando em neutropenia (Sobreira et al., 2004). Apenas um dos efeitos supracitados foram observados nesse relato. Uma diminuição dos leucócitos para o seu valor mínimo foi denotada na terceira semana de tratamento, conquanto, manteve-se dentro dos valores de referência. Por conta desta diminuição leucocitária, a dose da Ivermectina a $1 \%$ como terapia imunoestimulante foi aumentada.

Korystov et al. (2004) ressaltaram que a ivermectina consiste em uma droga alternativa potencial para o tratamento de TVT, uma vez que possui a capacidade inibir a glicoproteína $\mathrm{P}$ com baixa toxicidade. Thomas \& Coley (2003) elucidaram que tal proteína faz parte da membrana plasmática das células, sendo que sua função fisiológica não é totalmente esclarecida, não obstante, é sabido que ela é expressa nas adrenais, rins, fígado, cólon, cérebro, pulmões, sangue periférico e medula óssea normais. Faz parte da família de transportadores $\mathrm{ABC}$, capazes mover para o exterior da célula uma série de drogas, diminuindo o efeito deletério a níveis pouco letais. Destarte, por se tratar de um potente inibidor da glicoproteína-P que auxilia na inibição da resistência múltipla a drogas, é dita a sua associação com o protocolo da Vincristina (Lapa et al., 2012).

Nesse contexto, Lapa et al. (2012) denotaram que a Ivermectina aliada ao Sulfato de Vincristina no tratamento de TVT culminou em uma involução da massa tumoral em menor tempo, utilizando a dose de 0,2 a $0,6 \mathrm{mg} / \mathrm{kg}$, assim como Korystov et al. (2004). Por conseguinte, a Ivermectina pode reduzir a quantidade de administrações do quimioterápico de eleição e, desse modo, seus efeitos deletérios ao animal. Ademais, de acordo com Spinosa et al. (2002), estudos revelaram uma possível capacidade da Ivermectina de aumentar, de forma indireta, a população de células produtoras de imunoglobulinas (anticorpos) no baço, conferindo a este fármaco um efeito imunoestimulante apesar deste mecanismo não ser totalmente esclarecido. Ainda em relação aos parâmetros hematológicos do paciente, em se tratando da contagem de plaquetas, os valores permaneceram sem variações dignas de nota, situando-se dentro dos padrões de referência, divergindo do estudo realizado por Sobreira et al. (2004), em que é dito que o Sulfato de Vincristina induz a diminuição de megacariócitos e, por sua vez, das plaquetas, 
sendo a primeira, decorrente da ação deletéria do fármaco sobre megacariócitos culminando em megacariocitopenia e a segunda, pela toxicidade direta sobre plaquetas circulantes induzindo a uma diminuição em seu tempo de vida útil e culminando em trombocitopenia.

O tratamento clínico utilizando-se do Sulfato de Vincristina como protocolo quimioterápico é o mais indicado e, na maioria dos casos, há uma involução tumoral louvável (Ramadinha et al., 2016). Conquanto, fatores relacionados à localização extragenital do tumor têm atribuído característica de resistência a agentes quimioterápicos usados em seu tratamento (Daleck et al., 2008), fato este, não observado no presente relato.

O Sulfato de Vincristina promove uma interrupção da atividade nucleolar e, por conseguinte, estase da proliferação celular (Jericó et al., 2015). A administração do quimioterápico se dá por via endovenosa na dosagem de 0,5 a $0,75 \mathrm{mg} / \mathrm{m}^{2}$ ou 0,0125 a $0,025 \mathrm{mg} / \mathrm{kg}$ em aplicações semanais, com remissão total do tumor de 4 a 16 aplicações, sendo necessário o acompanhamento do perfil hematológico do animal por meio de hemograma a cada sessão (Andrade, 2008; Jericó et al., 2015; Tilley \& Smith, 2015). No presente relato, foi utilizada a dose de $0,5 \mathrm{mg} / \mathrm{m}^{2}$ na primeira sessão, alterando-se para $0,7 \mathrm{mg} / \mathrm{m}^{2}$ nas sessões subsequentes totalizando 6 aplicações, obtendo-se uma involução completa da massa tumoral. Em um relato de TVT ocular em um cão, realizado por Rodrigues et al., (2001), utilizando a mesma dosagem supracitada, a remissão do tumor foi clinicamente evidente a partir da primeira semana de tratamento, assim como observado no presente relato. Saratsis et al. (2000) afirmam que cinco a sete administrações do quimioterápico geralmente promovem uma total remissão do tumor, não havendo recidivas na grande maioria dos casos. Ramadinha et al. (2016) atingiram um índice de remissão total do tumor de 98,4\% utilizando-se do Sulfato de Vincristina como agente quimioterápico único em um limiar de 3 a 12 aplicações. O caso observado no presente relato condiz com os resultados obtidos pelos autores supracitados.

Apesar de o Sulfato de Vincristina ser o menos agressivo dentre os quimioterápicos disponíveis, a quimioterapia com o fármaco pode induzir alguns efeitos colaterais, dentre estes alopecia, febre, hipertensão, poliúria, anorexia, convulsão, disúria e paresia, devido à neuropatia periférica (Andrade, 2008; Martins et al., 2005). Ademais, mielossupressão, distúrbios gastrointestinais podem vir a ocorrer, culminando em êmese e diarreias em alguns casos, além de lesões no foco de aplicação devido ao extravasamento da droga durante a administração intravenosa (Booth \& McDonaldo, 1992; Martins et al., 2005). Nenhum dos efeitos adversos supracitados foi observado durante a terapia antineoplásica, haja vista o acompanhamento clínico semanal do paciente e os exames complementares solicitados.

\section{Conclusão}

Pode se inferir, por conseguinte, a importância do correto diagnóstico e tratamento do TVT na clínica veterinária. Tal neoplasia é altamente transmissível e tem se tornado frequente na rotina clínica de cães. Ressalta-se que apesar de já haver alguns relatos de resistência do tumor venéreo transmissível à Vincristina, principalmente em se tratando de tumores extragenitais, no presente relato, esta mostrou-se extremamente eficaz em associação à Ivermectina, na involução da massa tumoral.

\section{Referências bibliográficas}

Amaral, A. S., Gaspar, L. F. J., Silva, S. B., \& Rocha, N. S. (2004). Diagnóstico citológico do tumor venéreo transmissível na região de Botucatu, Brasil (estudo descritivo: 1994-2003). Revista Portuguesa de Ciências Veterinárias, 99, 167-171.

Amaral, A. V. C., Oliveira, R. F., Baylao, M. L., Luz, L. C., \& SantAna, F. J. F. (2012). Tumor venereo transmissivel intra-ocular em cao: relato de caso. Veterinaria e Zootecnia, 19(1), 79-86. DOI: https://doi.org/10.1590/S0103-84782001000100023

Andrade, S. F. (2008). Manual da Terapêutica Veterinária. Rocca.

Batista, J. S., Soares, H. S., Pereira, R. H. M. A., Aquino, P. A., Sousa, F. D. N., \& Nunes, F. das C. R. (2007). Tumor venéreo transmissível canino com localização intra-ocular e metástase no baço. Acta Veterinaria Brasilica, 1(1), 45-48. DOI: https://doi.org/10.21708/avb.2007.1.1.259

Booth, N. H., \& McDonaldo, L. E. (1992). Farmacologia e terapêutica em veterinária. Guanabara Koogan. 
Brandão, C. V. S., Borges, A. G., Ranzani, J. J. T., Rahal, S. C., Teixeira, C. R., \& Rocha, N. S. (2002). Tumor venéreo transmissível: estudo retrospectivo de 127 casos (1998-2000). Revista de Educação Continuada Em Medicina Veterinária e Zootecnia Do CRMV-SP, 5(1), 25-31. DOI: https://doi.org/10.36440/recmvz.v5i1.3280

Costa, M. (2008). Tumor venéreo transmissível canino. In C.R. Daleck, A. B. Nardi, \& S. Rodaski (Eds.), Oncologia em cães e gatos. Roca, Brasil.

Daleck, C R, De Nardi, A. B., Rodigheri, S. M., \& Motta, F. R. (2008). Neoplasia do sistema urinário. In Oncologia em cães e gatos (Vol. 1). Roca.

Daleck, Carlos Roberto, Fonseca, C. S., \& Canola, J. C. (2016). Oncologia em cães e gatos. Roca.

Drumond, K. O., Quessada, A. M., Silva, S. M. M. S., Costa, F. A. L., Silva, L. S., Pinho, F. A., \& Lopes, R. R. F. B. (2013). Transmissible venereal tumor treated with autohemotherapy. Acta Scientiae Veterinariae, 4l(1), 1-4.

Eze, C. A., Kene, R. O. C., \& Anyanwu, H. C. (2014). Comparative efficacy of surgery, vincristine sulphate and combined therapy of levamisole and Bacille Calmette Guerin vaccine in the treatment of transmissible venereal tumour-infected dogs. Comparative Clinical Pathology, 23(5), 1263-1267. DOI: https://doi.org/10.1007/s00580-013-1773-x

Filgueira, K. D. (2010). Tumor venéreo transmissível canino com localização primária e única em cavidade oral. Acta Scientiae Veterinariae, 38(1), 91-94. DOI: https://doi.org/10.22456/16799216.16552

Ginel, P. J., Molleda, J. M., Novales, M., Martin, E., Margarito, J. M., \& Lopez, R. (1995). Primary transmissible venereal tumor in the nasal cavity of a dog. Veterinary Record, 136, 222-223.

Huppes, R. R., Silva, C. G., Uscategui, R. A. R., De Nardi, A. B., Souza, F. W., Costa, M. T., Amorim, R. L., Pazzini, J. M., \& Faria, J. L. M. (2014). Tumor venéreo transmissível (TVT): Estudo retrospectivo de 144 casos. ARS Veterinaria, 30(1), 13-18. DOI: http://dx.doi.org/10.15361/21750106.2014v30n1p13-18

Jericó, M. M., Kogika, M. M., \& Andrade Neto, J. P. (2015). Tratado de medicina interna de cães e gatos. Guanabara Koogan.

Korystov, Y. N., Ermakova, N. V, Kublik, L. N., Levitman, M. K., Shaposhnikova, V. V, Mosin, V. A., Drinyaev, V. A., Kruglyak, E. B., Novik, T. S., \& Sterlina, T. S. (2004). Avermectins inhibit multidrug resistance of tumor cells. European Journal of Pharmacology, 493(1-3), 57-64. DOI: https://doi.org/10.1016/j.ejphar.2004.03.067

Lapa, F. A. S., Andrade, S. F., Gervazoni, E. R., Kaneko, V. M., Sanches, O. C., \& Gabriel Filho, L. R. A. (2012). Histopathological and cytological analysis of transmissible venereal tumor in dogs after two treatment protocols. Colloquium Agrariae, 8(1), 36-45.

Martins, M. I. M., Souza, F., Ferreira, F., \& Gobello, C. (2005). The canine transmissible venereal tumor: etiology, pathology, diagnosis and treatment. Recent Advances in Small Animal Reproduction, 25(7), 161-167.

Miller, W. H., Griffin, C. E., Campbell, K. L., \& Muller, G. H. (2013). Muller and Kirk's Small Animal Dermatology. Elsevier Health Sciences.

Mozos, E., Mendez, A., Gomez-Villamandos, J. C., Mulas, J. M., \& Perez, J. (1996). Immunohistochemical characterization of canine transmissible venereal tumor. Veterinary Pathology, 33(3), 257-263. DOI: https://doi.org/10.1177\%2F030098589603300301

Nielsen, S. W., \& Kennedy, P. C. (1990). Tumors of the genital systems. In M. J.E. (Ed.), Tumors of the genital systems. Nielsen S.W., Kennedy P.C. (1990). Tumors of the genital systems. In: Moulton J.E., Tumors in domestics animals. University of California Press, Berkeley, United States of América.

Ramadinha, R. R., Teixeira, R. S., Bomfim, P. C., Mascarenhas, M. B., França, T. N., Peixoto, T. C., Costa, S. Z. R., \& Peixoto, P. V. (2016). Resposta do tumor venéreo transmissível canino à quimioterapia com sulfato de vincristina e vimblastina. Brazilian Journal of Veterinary Medicine, 38(Supl. 1), 65-69.

Raposo, A. C. S. (2014). Tumor venéreo transmissível primário em conjuntiva palpebral de cão: relato de casos. Enciclopédia Biosfera, 10(19), 1803. 
Rodrigues, G. N., Alessi, A. C., \& Laus, J. L. (2001). Tumor venéreo transmissível intra-ocular em cão. Ciência Rural, 31(1), 141-143. DOI: https://doi.org/10.1590/S0103-84782001000100023

Santos, D. E., Silva, D. T., Toledo-Pinto, E. A., \& Lot, R. F. E. (2008). Tumor venéreo transmissível (TVT): Revisão de literatura. Revista Científica Eletrônica de Medicina Veterinária, 110(4), 1-7.

Santos, F. G. A., Vasconcelos, A. C., Moro, L., Nunes, J. E. S., \& Paixao, T. A. (2001). Apoptose no tumor venéreo transmissível canino: características morfológicas e evidenciação bioquímica. Arquivo Brasileiro de Medicina Veterinária e Zootecnia, 53(5), 557-562. DOI: https://doi.org/10.1590/S0102-09352001000500008

Santos, M. S. P., Nagashima, J. C., \& Montanha, F. P. (2001). Tumor venéreo transmissível (TVT) Revisão de literatura. Revista Científica Eletrônica de Medicina Veterinária, 16(1-15).

Santos, P. C. G., \& Shimizu, F. A. (2010). Aspectos anatomo histopatológico do tumor venéreo transmissível. Revista Científica Eletrônica de Medicina Veterinária, 3, 1-4.

Saratsis, P. H., Ypsilantis, P., \& Tselkas, K. (2000). Semen quality during vincristine treatment in dogs with transmissible venereal tumor. Theriogenology, 53(5), 1185-1192. DOI: https://doi.org/10.1016/S0093-691X(00)00263-6

Siddle, H. V, \& Kaufman, J. (2013). A tale of two tumours: comparison of the immune escape strategies of contagious cancers. Molecular Immunology, 55(2), 190-193. DOI: https://doi.org/10.1016/j.molimm.2012.10.017

Sobreira, L. F. R., Santana, A. E., Dias, M. A., Gama, F. G. V., \& Diniz, P. P. V. (2004). So Ação hematotóxica do sulfato de vincristina sobre a celularidade sanguínea central e periférica em cães. Ars Veterinária, 20, 169-174.

Spinosa, H. S., Górniak, S. L., \& Bernardi, M. M. (2002). Farmacologia aplicada à medicina veterinária. Guanabara Koogan.

Thomas, H., \& Coley, H. M. (2003). Overcoming multidrug resistance in cancer: an update on the clinical strategy of inhibiting p-glycoprotein. Cancer Control, 10(2), 159-165. DOI: https://doi.org/10.1177\%2F107327480301000207

Tilley, P. L., \& Smith, F. K. W. (2015). Five-minute Veterinary consult: canine and feline. John Wiley $\&$ Sons.

Recebido: 12 de março, 2020.

Aprovado: 8 de abril, 2020.

Disponível online: 8 julho, 2020 .

Licenciamento: Este artigo é publicado na modalidade Acesso Aberto sob a licença Creative Commons Atribuição 4.0 (CC-BY 4.0), a qual permite uso irrestrito, distribuição, reprodução em qualquer meio, desde que o autor e a fonte sejam devidamente creditados. 